\title{
Linfoma leucemizado em felino coinfectado com os vírus da imunodeficiência felina e da leucemia felina: relato de caso
}

\author{
[Lymphoma in leukemic phase in feline coinfected with feline immunodeficiency virus \\ and feline leukemia virus: case report] \\ T.M. Almeida ${ }^{1}$, R.P. Sousa Filho ${ }^{2,4}$, I.L. Rodrigues ${ }^{3}$, R.O. Cruz ${ }^{3}$, \\ A.P.R. Rodrigues ${ }^{4}$, I.N.G. Silva ${ }^{4}$ \\ ${ }^{1}$ Médico Veterinário - Universidade Federal Rural de Pernambuco - Garanhuns, PE \\ ${ }^{2}$ Catus - Medicina Felina - Fortaleza, CE \\ ${ }^{3}$ Aluna de graduação - Universidade Estadual do Ceará - Fortaleza, CE \\ ${ }^{4}$ Faculdade de Veterinária - Universidade Estadual do Ceará - Fortaleza, CE
}

\begin{abstract}
RESUMO
O presente trabalho teve por objetivo relatar um caso de linfoma leucemizado em um felino coinfectado com os vírus da imunodeficiência felina (FIV) e o da leucemia felina (FeLV). Foram realizados exames de hemograma, contagem de reticulócitos, mielograma, bioquímica, teste de imunocromatografia para FIV e FeLV, imunofluorescência indireta (IFA) para FeLV, radiografia torácica e citologia renal. Esse último exame revelou um linfoma extranodal. Foi determinante para a conclusão diagnóstica a associação dos sinais clínicos corroborados com a infiltração de elevada quantidade de células linfoblásticas na medula óssea, exibindo critérios citomorfológicos de malignidade, como mitoses atípicas, relacionadas à presença de corpúsculos linfoglandulares e material hematopoiético inter-relacionado. O linfoma é uma neoplasia relativamente comum em felinos, entretanto, a apresentação leucemizada é rara, podendo representar um desafio diagnóstico clínico, o que torna fundamental a inclusão da citologia medular na prática clínica dessa espécie.
\end{abstract}

Palavras-chave: gatos, hematologia clínica, medula óssea, neoplasia linfoproliferativa

\begin{abstract}
The present study aimed to report a case of lymphoma in leukemic phase in feline coinfected with feline immunodeficiency virus (FIV) and feline leukemia virus (FeLV). Blood counts, reticulocyte counts, bone marrow avaluation, biochemistry, immunochromatography assay for FIV and FeLV, indirect immunofluorescence (IFA) for FeLV, thoracic radiography and renal citology were performed. This last examination revealed extranodal lymphoma. The association of the clinical signs with the infiltration of a high number of lymphoblastic cells in the bone marrow with cytomorphological criteria of malignancy, atypical mitoses, lymphoglandular corpuscles and hematopoietic material were determinant for the diagnostic conclusion. Lymphoma is a relatively common neoplasm in felines, however the leukemic phase is rare and may represent a clinical diagnostic challenge, making it essential to include bone marrow cytology in the clinical practice of this species.
\end{abstract}

Keywords: cats, clinical hematology, bone marrow, lymphoproliferative disorder

\section{INTRODUÇÃO}

O linfoma é uma neoplasia de origem linfoide que se origina em tecidos sólidos e apresenta comportamento biológico maligno (Stockham e Scott, 2011). É o processo neoplásico hematopoiético mais comum no felino (Stützer $e t$

Recebido em 15 de novembro de 2017

Aceito em 2 de julho de 2018

E-mail: talles_zuca@hotmail.com al., 2011). Quanto à classificação morfológica, ressalta-se que as apresentações mediastínicas e multicêntricas são as mais comuns, entretanto, as formas intestinais e extranodais também são relatadas (Meichner e Bomhard, 2016). A linfoadenomegalia generalizada pode estar presente, mas não é um achado tão consistente nessa espécie, principalmente na conformação 
extranodal, na qual o envolvimento ocorre em estruturas não linfoides, apresentando-se de modo focal em órgãos como sistema nervoso central, estruturas sensoriais como olhos, fígado e rins (Kennedy e Little, 2017). Os sinais clínicos podem ser amplos e variados, secundários ao tipo específico da patologia. $\mathrm{O}$ termo linfoma leucemizado se refere à metastatização da neoplasia por via hematógena, infiltrando a corrente sanguínea e a medula óssea (Grindem et al., 2009). Retroviroses, mais especificamente o FeLV, que afeta diretamente o tecido hematopoiético, são fatores de predisposição ao linfoma, em que um animal infectado por esse vírus pode ter até 62 vezes mais chances de desenvolver essa neoplasia (Hartmann, 2012). O tratamento consiste em quimioterapia sistêmica à base de multifármacos, com a utilização de ciclofosfamida, vincristina e prednisona, ou até mesmo mediante a utilização individual de corticoterapia (Kennedy e Little, 2017). Objetivou-se, com o presente relato, descrever um caso de linfoma leucemizado em um felino coinfectado com FIV e FeLV.

\section{CASUÍSTICA}

Um felino, macho, sem raça definida, com seis anos de idade, foi atendido em clínica veterinária especializada em felinos, apresentando sialorreia sanguinolenta havia alguns meses, normorexia, disfagia e emagrecimento progressivo, sendo um animal com vários contactantes felinos, mas domiciliado. Ao exame físico, o animal mostrouse ativo, com mucosas orais acentuadamente eritematosas e hemorrágicas, halitose, quadro de gengivite-estomatite e renomegalia bilateral à palpação. Os demais parâmetros fisiológicos encontravam-se dentro da normalidade. Foram realizados, nesse primeiro momento, hemograma, bioquímica sérica com os analitos creatinina e fosfatase alcalina (FA), proteínas plasmáticas totais (PPT), radiografia torácica e teste de imunocromatografia para FIV e FeLV (SNAP COMBO anticorpo-FIV/antígeno-FeLV, Laboratório IDEXX ${ }^{\circledR}$, Westbrook, Maine, EUA).

No hemograma (Tab. 1), constatou-se pancitopenia, com moderada anemia macrocítica normocrômica, além da presença de moderados policromatófilos, leucopenia com neutropenia e linfopenia, monocitose relativa e acentuada trombocitopenia, mas associada à elevada quantidade de agregados plaquetários. A imunocromatografia para FIV e FeLV revelou-se positiva para ambas as retroviroses. A creatinina encontrava-se elevada, com valor de $3,3 \mathrm{mg} / \mathrm{dL}$. Os demais resultados dos exames complementares estavam dentro dos valores de referência para a espécie.

Em vista do exposto acima, relacionando-se à coinfecção viral, iniciou-se terapêutica com prednisolona $(2 \mathrm{mg} / \mathrm{kg})$ a cada 24 horas. No retorno, 10 dias após a abordagem clínica inicial, o quadro do paciente permaneceu inalterado, com melhoras clínicas não constatadas ao exame. Nesse momento, novo hemograma foi solicitado, além de contagem de reticulócitos e amostra medular para mielograma e IFA para detecção de antígeno p27 do FeLV nas células hematopoiéticas, utilizando-se anticorpos antiVLF (Primary Reagent for FeLV IFA, VRMD, Inc.) e o conjugado anti-IgG FITC (Secondary Reagent for IFA, VRMD, Inc.).

Diante disso, o segundo hemograma (Tab. 1) revelou pancitopenia, com acentuada anemia macrocítica e tendência hipocrômica, com moderados policromatófilos, discreta hipocromia e ocasionais corpúsculos de Howell-Jolly, leucopenia com neutropenia e tendência linfopênica, monocitose relativa, apresentando $5 \%$ de linfócitos reativos e $60 \%$ de monócitos ativados, além de acentuada trombocitopenia com plaquetas gigantes. A contagem de reticulócitos confirmou anemia arregenerativa. $\mathrm{O}$ mielograma (Fig. 1) constatou frequentes células de origem linfoide de característica linfoblástica, de tamanho médio a grande, exibindo anisocitose, alta relação núcleo:citoplasma, discreta a acentuada basofilia citoplasmática, anisocariose, cromatina de padrão finamente granular, nucléolos múltiplos e evidentes, anisonucleólise, figuras de mitose atípicas, além da presença de corpúsculos linfoglandulares, elevada ativação macrofágica com leucofagocitose e eritrofagocitose, e redução dos compartimentos proliferativos granulocítico neutrofílico, eritroide e megacariocítico. A IFA foi positiva para o FeLV.

Nesse contexto, foi confirmada mieloftise por neoplasia de origem linfoide, especificamente linfoma leucemizado, associado a acentuado processo histiocítico local e hipoplasia medular generalizada. 
Nesse sentido, foi continuada a terapêutica com prednisolona $(2 \mathrm{mg} / \mathrm{kg})$ a cada 24 horas, mas agora associada a marbofloxacina $(2,2 \mathrm{mg} / \mathrm{kg})$ a cada 24 horas e clorambucil (2,0mg/animal) a cada 48 horas.

O terceiro retorno se realizou 10 dias após o segundo, com o animal em uma condição clínica sem melhora significativa. Novo hemograma e bioquímica foram realizados, acrescentando-se a esse último exame dosagens de albumina, cálcio total e alanina aminotransferase (ALT). Nesse momento, a renomegalia tornou-se mais evidente, viabilizando punção citológica por agulha fina.

Assim, o terceiro hemograma (Tab. 1) revelou ainda bicitopenia, com anemia macrocítica normocrômica, leucócitos no intervalo, mas tendência leucopênica com neutropenia e monocitose, além de $90 \%$ de neutrófilos tóxicos, $30 \%$ de linfócitos reativos e $80 \%$ de monócitos ativados, com presença também de acentuada trombocitopenia sem plaquetas gigantes.

O exame citológico, associado aos dados clínicos, anatômicos e de diagnósticos complementares, excluindo-se o envolvimento de outros tecidos sólidos (Muniz et al., 2017), confirmou linfoma extranodal de origem primária renal (Fig. 2). Aproximadamente 20 dias depois do último retorno, o animal veio a óbito. A referida informação só foi divulgada pela tutora em um momento posterior, o que impossibilitou a realização de necropsia e exame histopatológico.

Tabela 1. Resultados dos hemogramas seriados de felino com linfoma leucemizado

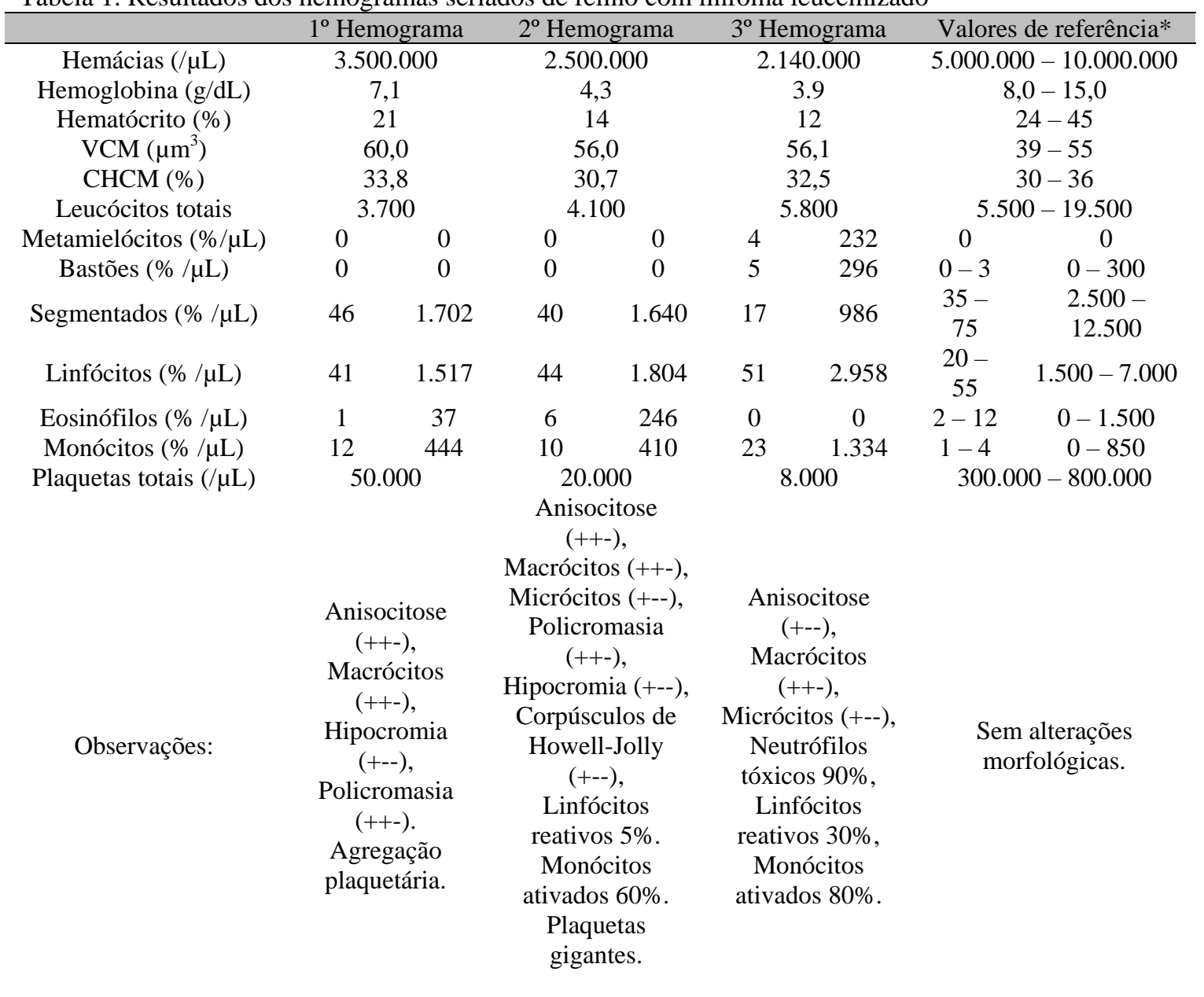

* Rizzi, t.e.; Clinkenbeard, k.d.; Meinkoth, j.h. (2010). 

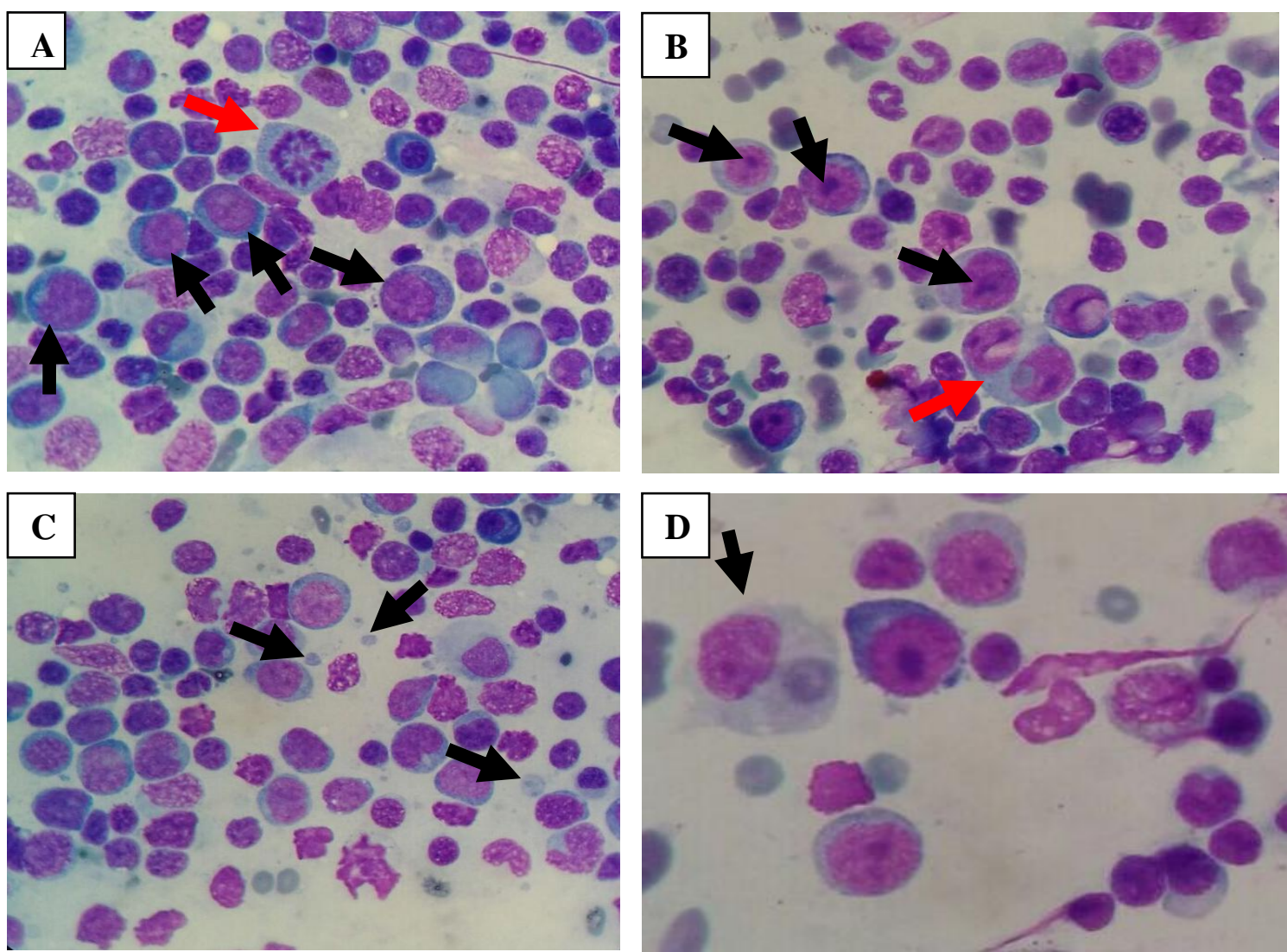

Figura 1. Amostras de medula óssea com linfoma leucemizado. A. Destaque para linfoblastos de tamanho médio a grande (setas pretas) e figura de mitose atípica (seta vermelha) (aumento de 1000x, Panótico Rápido - Laborclin $^{\circledR}$ ). B. Linfoblastos com nucléolos evidentes (setas pretas) e binucleados (seta vermelha) (aumento de 1000x, Panótico Rápido - Laborclin ${ }^{\circledR}$ ). C. Corpúsculos linfoglandulares (setas) (aumento de 1000x, Panótico Rápido - Laborclin ${ }^{\circledR}$ ). D. Eritrofagocitose relacionada à reação histiocítica local (seta) (aumento de 1000x, Panótico Rápido - Laborclin ${ }^{\circledR}$ ).

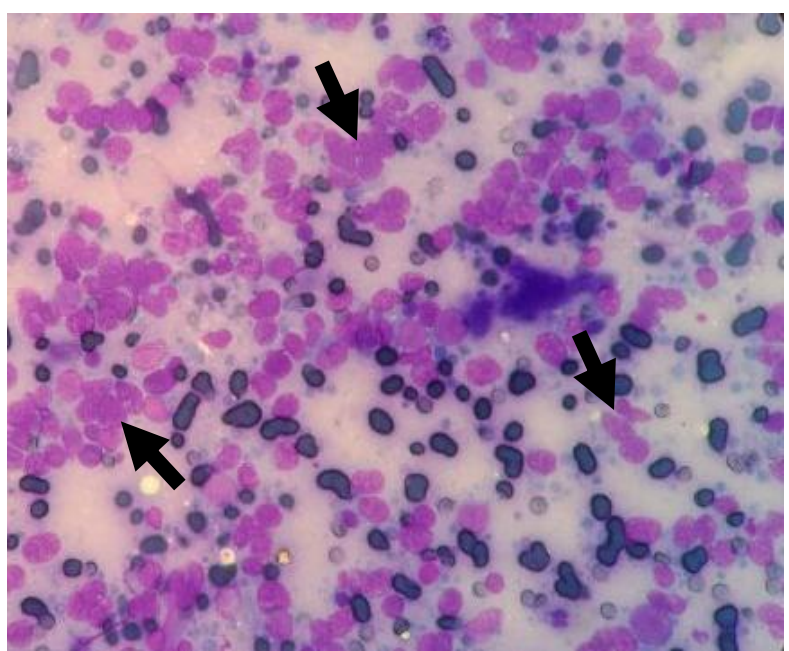

Figura 2. Amostra citológica renal, evidenciando população linfoblástica em monotonia, com acentuada fragilidade celular demonstrada pela presença de "núcleos livres ou nus" (setas) (aumento de 400x, Panótico Rápido - Laborclin ${ }^{\circledR}$ ).

\section{DISCUSSÃO}


Os sinais clínicos do linfoma dependerão da disfunção dos sistemas orgânicos afetados, principalmente em casos extranodais, cuja localização pode ser bastante variada, não atingindo diretamente um componente linfoide específico (Meichner e Bomhard, 2016). No presente caso, o paciente tinha 6 anos de idade, e os órgãos primários atingidos foram os rins. Nesse sentido, Tomé (2010) relata que gatos acometidos por linfomas renais possuem idade média de 7,5 anos, representando cerca de 5\% de todos os linfomas felinos. Muniz et al. (2017) relataram ainda que as evidências clínicas, associadas às informações patológicas, e, especialmente, a ausência de outros sítios neoplásicos em tecidos sólidos podem confirmar o linfoma de origem primária renal em gatos.

Quanto à infecção pelas retroviroses, é determinado que o FeLV é um dos agentes mais patogênicos na espécie felina, sendo correlacionado fortemente com o tecido sanguíneo, pois afeta de modo direto órgãos hematopoiéticos e linfoides (Hartmann, 2012), causando quadros de anemias arregenerativas, bicitopenias, pancitopenias, hipoplasias medulares, síndromes mielodisplásicas e neoplasias, principalmente linfoides e leucêmicas (Gelain et al., 2003; Hartmann, 2012). O FIV causa imunossupressão sistêmica e pode favorecer a instalação de quadros hematopatológicos (Gleich e Hartmann, 2009). Dessa maneira, o paciente em questão se enquadrava em um grupo de risco para o desenvolvimento de linfoma e de processos hematopatológicos gerais.

Em relação ao linfoma leucemizado, esse implica obrigatoriamente a análise de medula óssea e deve ser minuciosamente distinguido de quadros leucêmicos linfoides. Essa diferenciação pode ser difícil de ser realizada, entretanto, as análises de características particulares de caráter clínico e patológico auxiliam nesse propósito, como a ocorrência de corpúsculos linfoglandulares e a infiltração neoplásica parcial, não ocorrendo a predominância de um só tipo celular, como esperado na leucemia linfoide (Grindem et al., 2009).
As alterações hematológicas periféricas apresentadas pelo paciente são decorrentes de bicitopenias e pancitopenias por produção, em vista da mieloftise neoplásica (Weiss, 2008; Stützer et al., 2011). Adicionalmente, processos inflamatórios secundários, favorecidos pela imunodepressão, também maximizaram o quadro hematológico, visto que citocinas e quimiocinas inibem hematopoiese (Stacy e Harvey, 2016). As alterações hematoscópicas, representadas por neutrófilos tóxicos, linfócitos reativos e monócitos ativados, confirmam essa última conotação, culminando em um processo imunogênico ativo, progressivo e debilitante (Stockham e Scott, 2011). Destaca-se ainda que a anemia macrocítica constante, apesar da presença de policromatófilos, tinha caráter arregenerativo, devido à baixa contagem de reticulócitos. Essa possivelmente estava sendo potencializada pela presença dos macrócitos não policromáticos, que poderia estar relacionada a uma alteração eritroide megaloblástica promovida pela infecção pelo FeLV, ilustrando, assim, uma disematopoiese (Gelain et al., 2003; Stockham e Scott, 2011; Hartmann, 2012).

Em relação ao tratamento, não existe ainda consenso de protocolo, sendo esse um desafio terapêutico que apresenta prognóstico reservado. A utilização de um único fármaco, a prednisolona $(2 \mathrm{mg} / \mathrm{kg})$, a cada 24 horas, por duas semanas, reduzindo-se a dose para $1 \mathrm{mg} / \mathrm{kg}$ posteriormente, e assim por diante, é indicada e pode promover resultados satisfatórios (Kennedy e Little, 2017). A timomodulina pode ser utilizada para aumento da resposta imunogênica, e a antibioticoterapia para controle de infecções secundárias (Kennedy e Little, 2017). Após a constatação do quadro linfoide, a clorambucila foi instituída, por ser um princípio ativo eficaz para essa origem celular específica (Kennedy e Little, 2017).

Assim, reporta-se um achado incomum de linfoma leucemizado em felino. As evidências clínicas e laboratoriais conduziram ao diagnóstico definitivo. Dessa maneira, apesar de ser um processo raro, deve ser incluída como diagnóstico diferencial na medicina felina, principalmente em animais coinfectados com FIV e FeLV.

\section{REFERÊNCIAS}


GELAIN, M.E. et al. Disordini ematopoietici nella specie felina: aspetti classificativi ed associazione com le principali malattie e retrovirali. Veterinaria, v.17, p.59-67, 2003.

GLEICH, S.; HARTMANN, K. Hematology and serum biochemistry of feline immunodeficiency virus-infected and feline leukemia virus-infected cats. J. Vet. Intern. Med., v.23, p.552-558, 2009.

GRINDEM, C.B.; TY.LER, R.D.; COWELL, R.L. A medula óssea. In: COWELL, R.L. et al. Diagnóstico citológico e hematologia de cães e gatos. 3.ed. São Paulo: MedVet, 2009. p.423451.

HARTMANN, K. Clinical aspects of feline retroviruses: a review. Viruses, v.4, p.2684-2710, 2012.

KENNEDY, M.; LITTLE, S.E. Doenças virais. In: LITTLE, S.E. $O$ gato medicina interna. Rio de Janeiro: Roca, 2017. p.978-1046.

MEICHNER, K.; BOMHARD, W.V. Patient characteristics, histopathological findings and outcome in 97 cats with extranodal subcutaneous lymphoma (2007-2011). Vet. Comp. Oncol., v.14, p.8-20, 2016.

MUNIZ, I.M.; ANDRADE, E.R.; VOIGT, P.R. Primary renal lymphoma in domestic cat (Felis catus): case report. Vet. Zootec., v.24, p.120-124, 2017.
RIZZI, T.E.; CLINKENBEARD, K.D.; MEINKOTH, J.H. Normal hematology of the cat. In: WEISS, D.J.; WARDROP, K.J. Schalm's veterinary hematology. 6.ed. Ames: Blackwell Publishing, 2010. p.811-820.

STACY, N.I.; HARVEY, J.W. Bone marrow aspirate evaluation. Vet. Clin. Small Anim., v.47, p.31-52, 2016.

STOCKHAM, S.L.; SCOTT, M.A. Medula óssea e linfonodo. In: __ Fundamentos de patologia clínica veterinária. 2.ed. Rio de Janeiro: Guanabara Koogan, 2011. p.263-302.

STÜTZER, B. et al. Incidence of persistent viraemia and latent feline leukaemia virus infection in cats with lymphoma. J. Feline Med. Surg., v.13, p.81-87, 2011.

TOMÉ, T.L.S. Linfoma em felinos domésticos. 2010. 76f. Dissertação (Mestrado Integrado em Medicina Veterinária) - Faculdade de Medicina Veterinária, Universidade Técnica de Lisboa, POR.

WEISS, D.J. Bone marrow pathology in dogs and cats with non-regenerative immune-mediated haemolytic anaemia and pure red cell aplasia. $J$. Comp. Pathol., v.138, p.46-53, 2008. 